\title{
Distance Education During COVID-19 Pandemic: A College of Pharmacy Experience
}

\author{
Najla Altwaijry \\ Alnada Ibrahim $\mathbb{1 D}^{2,3}$ \\ Reem Binsuwaidan' \\ Lina I Alnajjar ${ }^{2}$ \\ Bshra A Alsfouk (1D) \\ Raghdah Almutairi (iD)
}

'Department of Pharmaceutical Sciences, College of Pharmacy, Princess Nourah Bint Abdulrahman University, Riyadh, Saudi Arabia; ${ }^{2}$ Department of Pharmacy Practice, College of Pharmacy, Princess Nourah Bint Abdulrahman University, Riyadh, Saudi Arabia; ${ }^{3}$ Department of Pharmaceutics, Faculty of Pharmacy, University of Khartoum, Khartoum, Sudan; ${ }^{4}$ College of Pharmacy, Princess Nourah Bint Abdulrahman University, Riyadh, Saudi Arabia
Correspondence: Alnada Ibrahim Department of Pharmacy Practice, College of Pharmacy, Princess Nourah Bint Abdulrahman University, Riyadh, Saudi Arabia

Tel +966503308360

Email alnada44@hotmail.com
Purpose: This study aimed at describing the experience of academic staff and students with distance education, during the COVID-19 pandemic, at a college of pharmacy in Saudi Arabia. Methods: This study used a mixed-method approach. The first phase implemented a survey that targeted both academic staff and students to evaluate their experiences with distance education during the COVID-19 pandemic. Then, a focus group discussion was conducted to explore, in-depth, their experience. The survey consisted of five domains as follows: readiness for the shift to distance education during the full and partial lockdown, perception towards distance education, barriers against distance education, and the acquisitions due to distance education. A five-point Likert scale was used to assess participants' responses to the different domains (mean score \pm standard deviation).

Results: Seventy-eight percent of the academic staff and $65 \%$ of the students responded to the survey. Participants' views were positive for readiness for the shift to distance education during the full lockdown (3.89 \pm 0.42 for academic staff and $3.82 \pm 0.50$ for students) with almost similar evaluation for the readiness during the blended learning period $(3.91 \pm 0.44$ for staff and $3.83 \pm 0.59$ for students). The findings showed a generally positive perception towards distance education (3.59 \pm 0.67 for academic staff and $3.47 \pm 0.64$ for students). The acquisitions due to distance education were also positive $(3.95 \pm 0.72$ for academic staff and $3.78 \pm 0.77$ for students). Nonetheless, some barriers that affected distance education were raised with an overall neutral view from both academic staff $(3.31 \pm 0.72)$ and students (3.31 \pm 0.64$)$, with different responses for the individual items. Qualitative findings from the focus group discussions explored the strengths, weaknesses, opportunities, and challenges, with emphasis on the areas for improvement.

Conclusion: Although the shift for distance education was out of a sudden, participants showed overall positive views about their experience with distance education and highlighted areas for improvement.

Keywords: Coronavirus crisis, remote education, pharmaceutical education, perception, blended learning, distance education

\section{Introduction}

Distance learning is a long-standing concept in higher education. It refers to learning mediated via technology devices when a physical distance exists between the learner and the educator. ${ }^{1}$ It is far from being a new phenomenon; tracing its history, distance learning originated in the earlier 18th century, in the shape of correspondence study to pave the way for desirous learners outside the city without a command to be on-site. Since then, it has gone through series of advancements and gained popularity, ${ }^{2}$ especially with the rapid development in technology 
innovation. In parallel, other modules in distance education have evolved such as blended learning (or hybridlearning) describing combination of face-to-face and technology-mediated instructions, ${ }^{3}$ offering a resilient, accessible learning experience. ${ }^{3,4}$ Presently, many educational institutions were compelled to use distance learning to synchronize the current COVID-19 situation. ${ }^{5-8}$

When the World Health Organization first announced COVID-19 as a global pandemic on March 11, 2020, governments had to use preventive policies to control the spread of the virus and suspended schools and universities attendance for an indefinite time. Higher education, shortly, responded to this huge shift and activated distance education, taking the advantage of existing learning supportive systems such as Blackboard and Moodle. ${ }^{6,9,10}$

Although this quick transition provided continuity to the learning process, it also heightened education disparities among students, especially those who live in rural areas or low-income countries, those with the pooreconomic state, and those who lack basic information technology skills. ${ }^{9,11}$ Such characteristics can hinder access to modern technology resources to support the distance learning movement. Taking into consideration that the present situation might persist for a longer period and propose a shift towards online learning for indefinite time. This situation will force educational institutions to be prepared and equipped with the necessary tools to ease the adoption of such a trend.

Various medical and health-related educational institutions have responded to the global pandemic by shifting to distance education. Varied experiences have been published, for example; in dental education where e-learning, and interaction during the education process, received appreciation from academic staff and students; ${ }^{12}$ in a medical school where more than half of the students and staff expressed their positive views on distance education; ${ }^{13}$ and in nursing education where distance education supported the continuation of the theoretical part of the courses but challenges arose for students with limited resources. ${ }^{14}$

In pharmacy education, the concept of distance learning was adopted before the COVID-19 pandemic in several institutes worldwide. The main goal was to enable students to undertake study programs outside the structure of their institutions and without requirements to be oncampus. Another goal was to reinforce education with innovative technologies, for example, the incorporation of video conferencing with traditional, entry-level to the
Doctor of Pharmacy program, and the introduction of synchronous, two-way live interaction learning. ${ }^{15}$ Another example is the provision of a distance learning program to obtain a Pharm.D degree under the "learning anywhere, anytime" premise. ${ }^{16}$ However, the emergence of this approach encountered challenges like technical issues, consistency of instructional materials within all sites, adjusting teaching style, and time to prepare materials. ${ }^{15,17,18}$ Other studies investigated the impact of distance learning on students' academic performance within either one or more courses of study and reported the effectiveness of such learning modes and their equivalency to traditional education with less difference size between scores. ${ }^{19,20}$

In response to the precautionary measures forced by governments to prevent COVID-19, a complete shift to distance learning was used as an alternative strategy to the suspension of students' attendance on campus. ${ }^{7}$ Varied levels of responses to the situation were reported. Some countries, for example, carried out off-campus students' research under remote supervision of faculty members. However, the capacity for e-learning, underequipped pharmacy schools, and internet access service were major challenges. $^{7,21,22}$ Other examples include activation of the asynchronous teaching for pharmacy education shortly to cope and expand learning accessibility; remote delivery of the educational content due to subscriptions to various E-Systems, expert's readiness, the inclusion of active learning in the curriculum, and training instructors to use online platform for teaching such as (Zoom). ${ }^{7,8,23}$

In the kingdom of Saudi Arabia, the Ministry of Education issued a notice, in March 2020, to suspend face-to-face teaching and learning and temporarily close all educational institutions because of the COVID-19 pandemic. Distance learning was activated, at different levels, through the use of online education platforms. For the subsequent academic year 2020-2021, the country regulated the education in higher institutions to maintain blended learning where lecturing was carried online and practical session and tutorials were carried on campus. Published literature from Saudi Arabia highlights experiences from some pharmacy schools. ${ }^{8,24}$ The aim of this study was to reflect the experience of a pharmacy school, during the COVID-19 pandemic, from the perspective of students and educators. The study also compared participants' views on full distance education and blended learning as modules in pharmacy education. The ultimate goal was that lessons can be learned from the different 
experiences and future thoughts can be discussed for more effective pharmacy education.

\section{Materials and Methods Study Design}

This study used a mixed-method approach. The first phase involved a cross-sectional survey that targeted both students and academic staff to evaluate their experiences with distance learning during the covid-19 pandemic. Then, a focus group discussion method was conducted with a group of students and academic staff with the purpose of in-depth exploration of their perspectives on the current situation and areas for improvement.

\section{Inclusion Criteria}

The study included all students and academic staff at the College of Pharmacy - Princess Nourah bint Abdulrahman University (PNU) during the academic year 2020-2021. PNU is a female-only university.

\section{Study Setting}

The study was conducted using an online survey with the target population. The focus group discussions were performed online, via Microsoft Teams, with a purposive sample of the target population who expressed their willingness to participate in the discussion sessions. Data collection took place from 15 November13 December 2020. The surveys were distributed to the target population through university email. To increase the response rate, two reminders were sent to the target population.

With respect to the distance education process, the College of Pharmacy - PNU has immediately shifted to distance education after the announcement made by the authorities for full lockdown in Saudi Arabia due to the COVID-19 pandemic. The College of Pharmacy has already the Blackboard Collaborate as the main e-learning system. Additionally, Microsoft Teams, as a communication application, is also in place. During the full lockdown (second term of the academic year 2019-2020), all teaching and assessment activities were performed remotely. For the first term of the academic year 2020-2021, as per the country regulations, blended learning was adopted in the college through performing lectures online, while the practical part of the subjects and tutorials, and exams were carried on site.

\section{Sample Size}

The study population consisted of all Pharm.D students registered for the academic year 2020-2021 ( $\mathrm{n}=365$ students) and all academic staff $(\mathrm{n}=54)$.

\section{Development of the Study Tools}

The study was performed using a survey for the first phase. The survey was developed based on the published literature, ${ }^{6-8,18,19,21,22}$ and the SWOC analysis (Strengths, Weaknesses, Opportunities, and Challenges), that was carried out by the College of Pharmacy at the beginning of the academic year for routine planning and improvement. Two versions of the survey were developed; one for academic staff and another one for students. Each survey consisted of six domains which were; characteristics of participants, views on the readiness for the shift to distance education during full lockdown (second term of the academic year 2019-2020), views on the readiness for the shift to distance education during the blended learning period (first term of the academic year 2020-2021), perception towards distance education, challenges facing the distance education process, and accomplishments from distance education.

The final surveys involved 40 questions and 38 questions for the academic staff's version and students' version, respectively. With respect to the academic staff's survey version, the face validity of the tool was carried out with two staff members, and then piloting was performed with other three staff members, who also judged the content validity of the two surveys based on their background and their responsibilities of the education process at the College of Pharmacy. For the students' version survey, five students were first face-validated the tool, then a pilot study with 15 students was carried out to inform the final version.

The questions about readiness for each academic staff's and students' survey were slightly different to match the position of each type of participants. The readiness was investigated with reference to individual's readiness and the institution's readiness. With respect to the academic staff, the readiness domain consisted of eight questions for period 1 and nine questions for period 2. Regarding students, the readiness was assessed using seven items for period 1 and seven items for period 2. Responses to each question were rated on a 5-point Likert scale (strongly disagree $=1$, disagree $=2$, neutral $=3$, agree $=4$, strongly agree $=5$ ) . Responses to this domain were calculated using the 
weighted mean for each question and the overall mean for the domain. The trend of participants' views was calculated with reference to the weighted as follows: strongly disagree $=1-1.79$, disagree $=1.8-2.59$, neutral $=2.60-3.39$, agree $=$ $3.40-4.19$, and strongly agree $=4.20-5$ ).

Regarding perception, six items and nine items were used to investigate the staff's and the students' perceptions, respectively. A 5-point Likert scale was used for these questions ( $1=$ very untrue of me, $2=$ untrue of me, $3=$ neutral, $4=$ true of me, and $5=$ very true of me). The trend of participants' perception towards distance education was calculated with reference to the weighted mean as follows: very untrue of $m e=1-1.79$, untrue of $m e=1.8-2.59$, neutral $=2.60-3.39$, true of $\mathrm{me}=3.40-4.19$, and very true of $\mathrm{me}=$ 4.20-5). The results of this domain are shown in Table 1.

Responses to the barriers domain were investigated using a 5-point Likert scale as follows: $1=$ not at all a barrier, $2=$ small barrier, $3=$ neutral, $4=$ large barrier, and $5=$ very large barrier. The trend of participants' views on the barriers towards distance education was calculated with reference to the weighted mean as follows: not at all a barrier $=$ $1-1.79$, small barrier $=1.8-2.59$, neutral $=2.60-3.39$, large barrier $=3.40-4.19$, and very large barrier $=4.20-5$.

Regarding acquisitions, responses to each question were rated on a 5 -point Likert scale (strongly disagree $=1$, disagree $=2$, neutral $=3$, agree $=4$, strongly agree $=5$ ) . Responses to this domain were calculated using the weighted mean for each question and for the overall mean for the domain. The trend of participants' views was calculated with reference to the weighted as follows: strongly disagree $=1-1.79$, disagree $=1.8-2.59$, neutral $=2.60-3.39$, agree $=3.40-4.19$, and strongly agree $=4.20-5$ )

For the purpose of the focus group discussions with students and staff, a topic guide was prepared for each

Table I Academic Staff's and Students' Perception Towards Distance Education

\begin{tabular}{|c|c|c|c|c|c|}
\hline \multicolumn{3}{|l|}{ Academic Staff $(n=38)$} & \multicolumn{3}{|c|}{ Students $(n=223)$} \\
\hline Statement & $\begin{array}{l}\text { Weighted } \\
\text { Mean } \pm \\
\text { SD }\end{array}$ & $\begin{array}{l}\text { Overall } \\
\text { Trend }\end{array}$ & Statement & $\begin{array}{l}\text { Weighted } \\
\text { Mean } \pm \\
\text { SD }\end{array}$ & $\begin{array}{l}\text { Overall } \\
\text { Trend }\end{array}$ \\
\hline The amount of interaction with students. & $3.97 \pm 0.592$ & $\begin{array}{l}\text { True of } \\
\text { me }\end{array}$ & The amount of interaction with instructors & $3.43 \pm 0.840$ & $\begin{array}{l}\text { True of } \\
\text { me }\end{array}$ \\
\hline The quality of interaction with students & $3.29 \pm 1.183$ & Neutral & The quality of interaction with instructors & $3.21 \pm 0.875$ & Neutral \\
\hline $\begin{array}{l}\text { The distance education provides a reliable } \\
\text { means of communication }\end{array}$ & $3.61 \pm 0.790$ & $\begin{array}{l}\text { True of } \\
\text { me }\end{array}$ & The amounts of interaction with classmates & $3.44 \pm 1.029$ & $\begin{array}{l}\text { True of } \\
\text { me }\end{array}$ \\
\hline $\begin{array}{l}\text { Time management during distance } \\
\text { education period }\end{array}$ & $3.58 \pm 0.919$ & $\begin{array}{l}\text { True of } \\
\text { me }\end{array}$ & The quality of interaction with classmates & $3.35 \pm 0.936$ & Neutral \\
\hline $\begin{array}{l}\text { The overall achievement of learning } \\
\text { outcomes for knowledge and cognitive } \\
\text { skills are comparable to that in the on-site. }\end{array}$ & $3.37 \pm 1.025$ & Neutral & $\begin{array}{l}\text { The distance learning process provides } \\
\text { a personal experience that can be compared } \\
\text { to the experience in the classroom }\end{array}$ & $3.49 \pm 0.999$ & $\begin{array}{l}\text { True of } \\
\text { me }\end{array}$ \\
\hline \multirow[t]{4}{*}{ Comfort to teach online for a longer period } & $3.7 I \pm 0.835$ & $\begin{array}{l}\text { True of } \\
\text { me }\end{array}$ & $\begin{array}{l}\text { Time management during distances learning } \\
\text { period }\end{array}$ & $3.34 \pm 1.022$ & Neutral \\
\hline & & & $\begin{array}{l}\text { Comfort to conduct homework's and } \\
\text { assignments during distance learning }\end{array}$ & $3.42 \pm 1.116$ & $\begin{array}{l}\text { True of } \\
\text { me }\end{array}$ \\
\hline & & & $\begin{array}{l}\text { Academic achievements satisfaction during } \\
\text { the distance education period }\end{array}$ & $3.26 \pm 1.093$ & Neutral \\
\hline & & & Comfort to study online for a longer period & $3.76 \pm 0.888$ & $\begin{array}{l}\text { True of } \\
\text { me }\end{array}$ \\
\hline Overall mean of the domain & $\begin{array}{l}3.59 \pm \\
0.6731\end{array}$ & $\begin{array}{l}\text { True of } \\
\text { me }\end{array}$ & Overall mean of the domain & $3.47 \pm 0.64$ & $\begin{array}{l}\text { True of } \\
\text { me }\end{array}$ \\
\hline
\end{tabular}


category. This was based on elaborating more on the main sections of the survey and participants' responses.

\section{Data Processing and Analysis}

Analysis of the survey data was conducted using the Statistical Package for Social Sciences (SPSS for Windows, version 24). Each question in the survey was coded. Descriptive statistics were carried out such as frequencies and percentages. For the qualitative data generated from the focus group discussions, thematic analysis ${ }^{25}$ was applied. Three authors in this paper went through coding and labeling of the data generated from the focus group discussions, grouping it into themes, and examining it to make sure that all the expressions of each theme have been considered.

\section{Ethical Considerations}

An ethical review of the study was obtained from the Institutional Review Board at Princess Nourah bint Abdulrahman University (IRB Log Number: 20-0464). Before study commencement, participants were asked about their willingness to participate in the research. A consent form was sent together with the survey link. The consent form gave information about the study and participants' rights. The online survey also gave an introduction about the study, and there was a statement indicating that the participants have read the information about the study and they agree to participate. For the qualitative part, written consent was obtained from those who participated in the focus group discussion. The participants informed consent included publication of anonymized responses.

\section{Results}

\section{Characteristics of the Study Participants}

Two surveys were used in this study: one for academic staff and another one for students. There were 49 eligible academic staff members (after excluding the five members who participated in the face validity and the pilot study), of whom, a total of 38 responses were received, giving a response rate of $78 \%$. Of the respondents, $55 \%$ were assistant professors and above (and the remaining were lecturers and teaching assistants), $45 \%$ had an experience of $6-15$ years in teaching, whereas $37 \%$ and $18 \%$ had less than 6 years and more than 15 years teaching experience, respectively.

Concerning students, the survey was distributed to 345 (after excluding the 20 students who participated in face validity and the pilot study). Of the students, 223 responded to the survey with a response rate of $65 \%$. Participants' academic levels were as follows: $23 \%$ at level $11,18 \%$ at level $9,20 \%$ at level $7,18 \%$ at level 5 , and $21 \%$ at level 3 .

\section{Reliability Analysis of the Surveys' Domains}

The reliability (internal consistency) of the survey domains was evaluated. Analysis of the staff's survey showed the following results for Cronbach's alpha for the different domains: 0.777 for readiness during period $1,0.813$ for readiness during period 2, 0.835 for perception, 0.853 for barriers, and 0.837 for acquisition. For the students' survey, the following values of Cronbach's alpha for the different domains were obtained: 0.791 for readiness during period 1, 0.839 for readiness during period 2, 0.928 for perception, 0.753 for barriers, and 0.907 for acquisition. This is an indication of

\section{Views on the Readiness for the Shift to Distance Education}

Both academic staff and students were asked about their views on the readiness for the shift to distance education during full lockdown (second term of the academic year 2019-2020 - period 1), and during the blended learning (first term of the academic year 2020-2021 - period 2). The findings of this section are illustrated in Figure 1 (for academic staff) and Figure 2 (for students). All items showed an overall trend of agree (3.40-4.19) during the two periods investigated. Participants' views were reported as agree for: readiness for the shift to distance education during the full lockdown (3.89 \pm 0.42$)$, and readiness for the shift to distance education during the blended learning (3.91 \pm 0.44$)$

For the readiness during the blended learning period (period 2), an additional statement was added which is statement \# 9; "I am well prepared to carry out any future distance education". This statement was added to sum up the staff's views after they experienced distance education for two semesters. The score for this item was $4.05 \pm 0.695$ (Mean \pm SD).

In relation to students, all items showed an overall trend of agree (3.40-4.19) during the two periods investigated; $3.82 \pm 0.50$ for the shift to distance education during the full lockdown period, and $0.83 \pm 0.59$ for the blended 


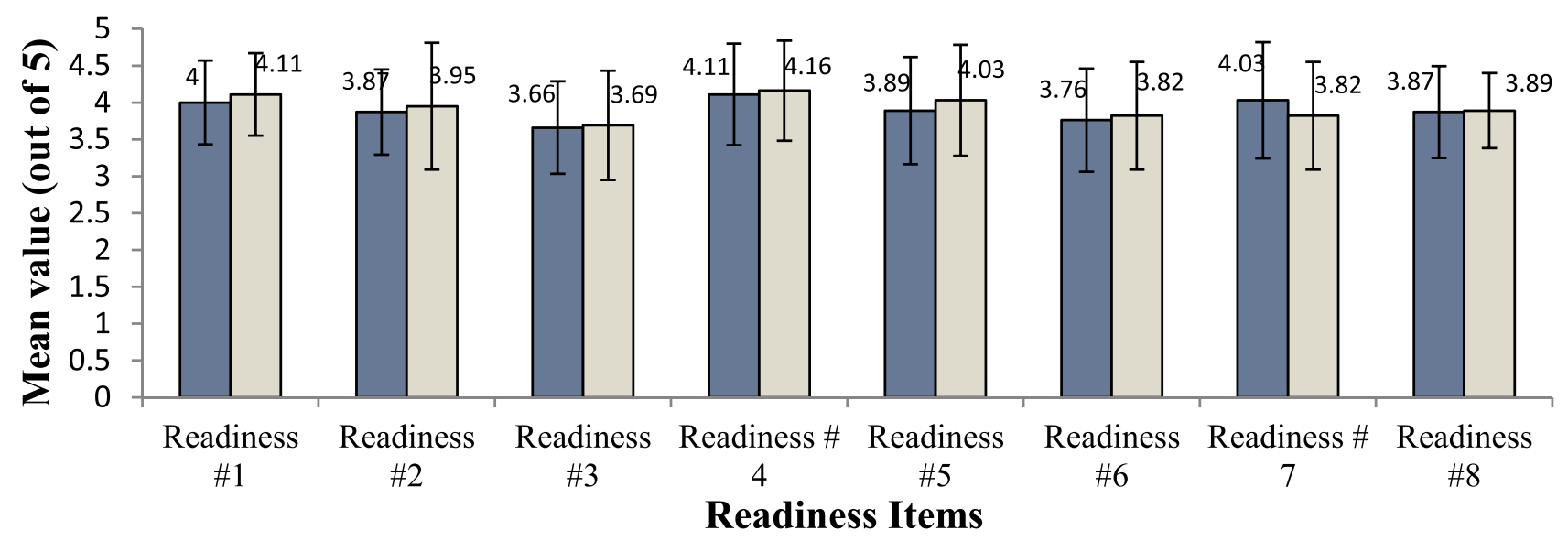

$\square$ Readiness during full distance education $\quad \square$ Readiness during blended learning period

Figure I Academic staff's views (mean $\pm S D$ ) on the readiness for the shift to distance education during the full distance education and blended learning ( $\mathrm{n}=38$ ). Notes: Key to readiness items: Readiness \#I: The university has a system that supports distance education, Readiness \#2: the university has a system that supports e-learning (before the pandemic), Readiness \#3: I was able to easily access the Internet for my teaching tasks, Readiness \# 4: I had satisfactory computer skills to deal with distance education, Readiness \#5: I had good background and experience that facilitate my involvement in distance education, Readiness \#6: the co-instructors in the course had sufficient background and experience that facilitate their involvement in distance education, Readiness \# 7: An adequate technical support during distance education was provided, to me, by the college/university, Readiness \#8: An adequate training was provided, by the college/university, to academic staff to perform their distance educational tasks.

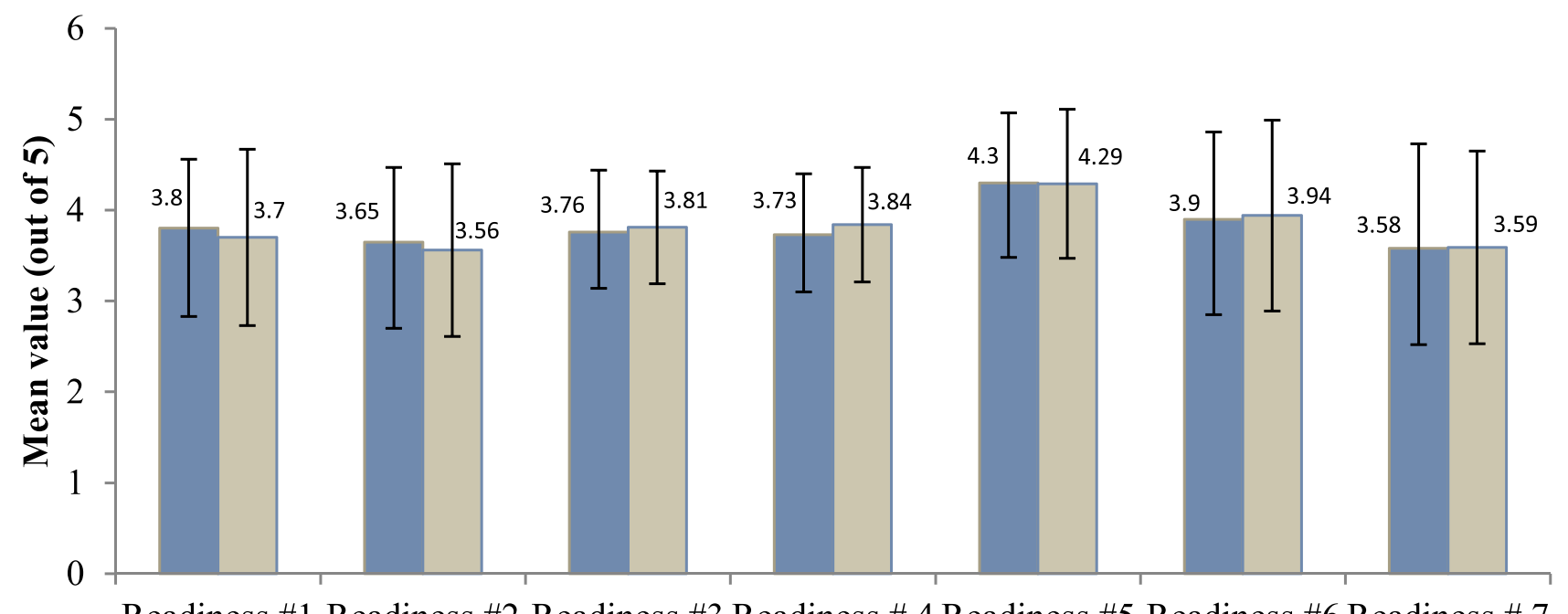

Readiness \#1 Readiness \#2 Readiness \#3 Readiness \# 4 Readiness \#5 Readiness \#6 Readiness \# 7

\section{Readiness items}

Readiness during full distance education $\quad \square$ Readiness during blended learning period

Figure 2 Students' views (mean \pm SD) on the readiness for the shift to distance education during the full distance learning and blended learning $(n=223$ ); $n=223$ for responses during full distance learning, and $n=172$ for responses during blended learning as students on semester II were removed from the analysis since they were in the internship year during the first term of the academic year 2020-2021.

Notes: Key to readiness items: Readiness \#I: The College of Pharmacy has a system that supports distance education, Readiness \#2: The College of Pharmacy provided me with the appropriate technical support during the distance education period, Readiness \#3: The faculty members had sufficient knowledge and familiarity with e-learning systems, Readiness \# 4: academic staff members' readiness for distance education was good, Readiness \#5: I had adequate computer skills to deal with distance education, Readiness \#6: I had a good internet connection that enabled me to study remotely, Readiness \# 7: Overall, I was well prepared to complete the semester by distance education. 
The technical issues during the assessment process

The technical issues during the teaching process Long-time focus on computer screen Limited communication compared to face to face Students' readiness for online learning Lack of motivation Lack of past experience Limited technology experience Limited Internet access



Figure 3 Academic staff's views on the perceived barriers against the distance education process $(n=38)$.

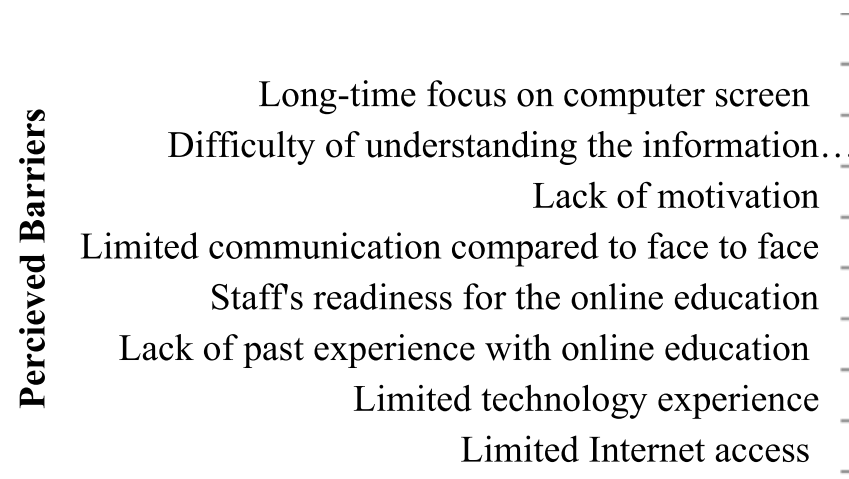

learning period. Responses for the
domain are presented in Figure 2.

\section{Perception Towards Distance Education}

Academic staff and students were asked about their perception towards the process of distance education. The findings of this section are illustrated in Table 1 .

\section{Barriers Towards Distance Education}

The study participants were asked about their views on the perceived barriers against the process of distance education. The findings of this section are presented in Figure 3 (for academic staff's responses), and Figure 4 (for students' responses)

For academic staff, the technical issues during lecturing and assessments were considered the biggest barrier, then the effort paid due to long-time facing the screen,

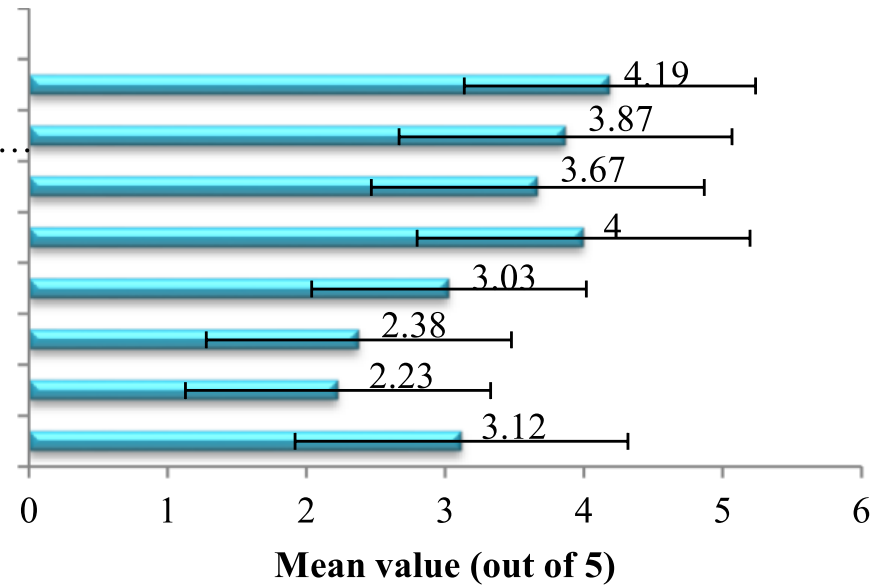

Mean value (out of 5)

Figure 4 Students' views (mean $\pm S D$ ) on the perceived barriers against the distance education process $(n=223)$.

followed by the limited communication compared to faceto-face teaching.

For students, on the other hand, the main barrier for them was the effort paid due to long-time facing the screen followed by the lacking of effective communication compared to face to face. Students found to face difficulty in understanding the information which affects their motivation.

\section{Acquisitions from Distance Education}

The perceived acquisitions due to the shift to distance education were examined, and the findings are illustrated in Table 2.

\section{Focus Group SWOC Analysis}

A group of academic staff involving eight members, and a group of nine students from different academic levels, participated in separate group discussions. The academic 
Table 2 Academic Staff's and Students' Perceived Acquisitions Due to the Distance Education

\begin{tabular}{|c|c|c|c|c|c|}
\hline \multicolumn{3}{|l|}{ Academic Staff(n = 38) } & \multicolumn{3}{|c|}{ Students $(n=223)$} \\
\hline Statement & $\begin{array}{l}\text { Weighted } \\
\text { Mean } \pm \text { SD }\end{array}$ & $\begin{array}{l}\text { Overall } \\
\text { Trend }\end{array}$ & Statement & $\begin{array}{l}\text { Weighted } \\
\text { Mean } \pm \text { SD }\end{array}$ & $\begin{array}{l}\text { Overall } \\
\text { Trend }\end{array}$ \\
\hline $\begin{array}{l}\text { Delivery of lectures from } \\
\text { anywhere }\end{array}$ & $4 .|8 \pm 0.80|$ & Agree & Attending lectures from anywhere & $3.84 \pm 1.138$ & Agree \\
\hline $\begin{array}{l}\text { Improvement of time organization } \\
\text { and utilization }\end{array}$ & $3.63 \pm 1.101$ & Agree & $\begin{array}{l}\text { Enhancement of time management } \\
\text { skills }\end{array}$ & $3.25 \pm 1.068$ & Neutral \\
\hline Enhancement of computer skills & $4.13 \pm 0.704$ & Agree & Enhancement of e-learning skills & $3.87 \pm 1.057$ & Agree \\
\hline \multirow[t]{3}{*}{ Enhancement of teaching skills } & $3.84 \pm 0.855$ & Agree & $\begin{array}{l}\text { Enhancement of independent learning } \\
\text { skills }\end{array}$ & $4.07 \pm 0.783$ & Agree \\
\hline & & & $\begin{array}{l}\text { Enhancement of the acquisition of } \\
\text { scientific knowledge }\end{array}$ & $3.12 \pm 1.247$ & Neutral \\
\hline & & & Avoid daily transportation & $4.39 \pm 0.757$ & Agree \\
\hline Overall mean of the domain & $3.95 \pm 0.72$ & Agree & Overall mean of the domain & $3.82 \pm 0.49$ & Agree \\
\hline
\end{tabular}

staff participants were from the two departments in the College of Pharmacy; Department of Pharmaceutical Sciences and Department of Pharmacy Practice. The purpose of the discussions was to elaborate on the findings from the surveys.

The discussion focused at first on the experiences of the participants during the full distance education and during blended learning for the courses that involve practical sessions and tutorials. The discussion took the form of SWOC analysis where participants had the opportunity to express their views about the strengths, weaknesses, opportunities, and challenges that face the distance education process. The themes that emerged from the two group discussions were merged and are presented in Table 3.

Additionally, the focus group discussion explored participants' views on the areas that need improvement which included:

- Enhancement of distance education platforms

- Enhancement of the communication between academic staff and students

- Enhancement of synchronous interaction

- More training coaches on time management during distance education

- More training courses for all beneficiaries to better utilize the available resources

- More technology integration into the distance education process

\section{Discussion}

This study was carried out at the College of Pharmacy PNU to investigate academic staff's and students' experiences with distance education during the COVID-19 pandemic and compared their experience during distance and blended learning. Participants in this study represented academic staff with different academic ranks and teaching experience, and students from different years of study.

The current study reports the findings of a college of pharmacy experience in an educational environment where courses are delivered, in the normal situation, through inclassroom teaching, laboratory teaching, and experiential training, in addition to other activities. The situation has changed during the pandemic to distance education for the second term of the academic year 2019-2020, and to blended learning during the academic year 2020-2021. It is worth mentioning that the experience of students who were on the experiential training at the time of the study, was not investigated here. It will be emphasized on in a separate research.

The study started with examining participants' views on the readiness to shift to distance education when the decision was a sudden one because of the pandemic, and their views during the academic year 2020-2021 or what is considered here blended learning period. The main areas of the domain were about participants' capabilities, the efficiency of available learning systems, and the technical support provided. Responses to this domain, during the 
Table 3 Main Themes and Supporting Quotes from Focus Group Discussion with Academic Staff $(n=8)$ and Students $(n=9)$

\begin{tabular}{|c|c|c|c|}
\hline Strengths & Weakness & Opportunities & Challenges \\
\hline $\begin{array}{l}\text { - Availability of different online } \\
\text { platforms } \\
\text { - Familiarity of staff with online } \\
\text { platforms } \\
\text { - Availability of IT support } \\
\text { throughout the day } \\
\text { - Continuous training } \\
\text { - Visual aids to support } \\
\text { E-Learning } \\
\text { - Skills enhancement } \\
\text { - Students support. } \\
\text { Overall, make continuation of the } \\
\text { education process. }\end{array}$ & $\begin{array}{l}\text { - Difficulty to handle group } \\
\text { sessions online } \\
\text { - Missing objectives that could } \\
\text { not be met during the online } \\
\text { process } \\
\text { - Reduced quality of } \\
\text { communication compared to } \\
\text { onsite education. } \\
\text {-Internet problems } \\
\text { - Communication with students } \\
\text { need more time } \\
\text { - Reduced active learning } \\
\text { compared to onsite education } \\
\text { - Difficulty in managing students } \\
\text { participation and attendance } \\
\text { - Online assessment validity } \\
\text { issues. } \\
\text { Health issues: may affect one's } \\
\text { vision }\end{array}$ & $\begin{array}{l}\text { - Open the door to the } \\
\text { development of new teaching } \\
\text { approaches } \\
\text { - Increase the number of students } \\
\text { that can be reached. } \\
\text { - Time-saving if merging students } \\
\text { groups is appropriate. } \\
\text { - Sessions recording can be used } \\
\text { to make the material available } \\
\text { - Can add online courses Add E- } \\
\text { learning courses. } \\
\text { - Lots can be done online e.g, } \\
\text { meetings }\end{array}$ & $\begin{array}{l}\text { - Maintaining good internet } \\
\text { access } \\
\text { - Enhancement of technology } \\
\text { skills to deal with technical issues } \\
\text { - Maintaining functionality of the } \\
\text { online platforms } \\
\text { - Isolation during online process. } \\
\text { - How to maintain valid students } \\
\text { assessment process. } \\
\text { - How to effectively } \\
\text { communicate with others } \\
\text { - home may not be the ideal place } \\
\text { for having classes }\end{array}$ \\
\hline $\begin{array}{l}\text { Supporting quotes } \\
\text { “....at first I got panic when the } \\
\text { shift to full distance education } \\
\text { took place ... but with the } \\
\text { experience I have with some } \\
\text { distance educational platforms, } \\
\text { with the continuous IT support } \\
\text { we were receiving, things went } \\
\text { more than I expected ... now } \\
\text { I feel more comfortable teaching } \\
\text { online ...” Academic staff I } \\
\text { “. I feel relaxed with the process } \\
\text { of distance education ... for the } \\
\text { majority of the courses I am } \\
\text { taking now. the situation may } \\
\text { differ when I move to higher levels } \\
\text { of study ... " Student } 2\end{array}$ & $\begin{array}{l}\text { Supporting quotes } \\
\text { “... as a lab instructor, teaching } \\
\text { fully online will not allow students } \\
\text { to meet some of the learning } \\
\text { outcomes, with blended learning } \\
\text { feel more relaxed when I think of } \\
\text { my students and the lab skills they } \\
\text { should acquire ... " Academic } \\
\text { staff } 3 \\
\text { “... I experienced some technical } \\
\text { issue while I was performing an } \\
\text { online exam ... being under lots } \\
\text { of pressure will not allow me to } \\
\text { think of distance education as } \\
\text { a good option." Student } 4\end{array}$ & $\begin{array}{l}\text { Supporting quotes } \\
\text { "... I Learn lots of things in } \\
\text { a short period of time because of } \\
\text { the emergency situation and the } \\
\text { shift to distance education, which } \\
\text { I could not do in normal time." } \\
\text { Academic staff } 2 \\
\text { "I am making full use of the } \\
\text { recoded lectures ... sometimes } \\
\text { during the lecture you cannot } \\
\text { follow what is being said ... it is } \\
\text { very good to have a backup." } \\
\text { Student I }\end{array}$ & $\begin{array}{l}\text { Supporting quotes } \\
\text { “... a challenging issue is how to } \\
\text { make good use of the technology } \\
\text { infrastructure that we have. but } \\
\text { time constrain, it is difficult ... for } \\
\text { me distance education is a time } \\
\text { consuming process ... the course } \\
\text { I teach requires lots of } \\
\text { preparatory work which is } \\
\text { reduced when meeting face to } \\
\text { face with students ... " Academic } \\
\text { staff } 2 \\
\text { "I am a kind of a very social } \\
\text { person ... I enjoy face-to-face } \\
\text { discussions with my classmates } \\
\text { and my instructors ... I learn a lot } \\
\text { from the face-to-face } \\
\text { communication. I do not think } \\
\text { I can cope with the online } \\
\text { communication ..." } \\
\text { Student I }\end{array}$ \\
\hline
\end{tabular}

two periods, showed varied mean scores, but there are all in the positive range of the views. Overall, participants showed positive views about their readiness and the college's readiness for a shift to distance education during the two periods under study.

In order to accept or cope with any new situation, having a positive opinion about it is of great importance.
Such a finding, reported in this study, may open the door for more discussion with the beneficiaries with the aim of improving their experiences, and for better utilization of the available resources. Even before the pandemic, academic staff and students were familiar with many components related to the use of some e-learning management systems and distance educational platforms (as required by 
the institution), but the actual utilization of these platforms may vary among the beneficiaries. At the College of Pharmacy, before the pandemic, there are online courses (in the preparatory year), blended courses (some college courses for instance pharmaceutical ethics), as well as use of technology in teaching, assessment, and communication in all college courses as part of the course activities. Immediately, after the decision of shifting to full distance education was made by the authorities, the College of Pharmacy - PNU, prepared a risk management plan for the education process. A comprehensive guide, which was in line with the university one, was, promptly, provided to all beneficiaries, and updates were also well timed. Different committees were established, in response to the emergent situation, to aid in the management of the education process. Technical support was provided at the university and college level throughout the day. This might explain the participants' positive feedback on many items related to the readiness to the shift to distance education. Positive opinion about the transition to distance education in the pharmacy field was also reported by some studies that investigated students' and academic staff's experiences. ${ }^{8,24}$ An analytical overview of various responses of higher educational institutions in the region of Gulf Cooperation Council also highlighted the positive impact of the already established distance education infrastructure on the transformation process. ${ }^{26}$ In contrast, when some basic infrastructure represents a concern, distance education might be a challenging process. ${ }^{21,27}$

After having participants' views on the readiness to the shift to distance education, an important issue was how they generally perceived distance education after the experience they went through. Participants' perception toward distance education was generally positive. Nevertheless, some components of the perception showed an overall score of "neutral". This signifies that these areas did not receive positive views and a significant number of participants' found them a challenge. The areas of concern were teaching staff's views on the quality of interaction with students, the overall achievement of the learning outcomes, whereas students showed neutral feedback on the quality of interaction with instructors and classmates in addition to some concerns regarding time management and overall academic achievements. In fact, all the mentioned areas represent challenging issues, and they are reported as concerns in the literature. , $21,28^{\text {Interaction is }}$ a fundamental component of any education process, increasingly the online one. The amount of interaction received positive views by study participants; however, the quality of interaction was a concern. This issue was also emphasized on during the focus group discussion. The impact on the quality of interaction between the preceptors, students and peers might be one of the reasons behind the neutral perspective toward the overall achievement of the learning outcomes in both academics and students especially skills and values outcomes. This calls for improvement in this respect as interaction is the key element in students' understanding and skills improvement. Indeed, the instructor plays a major role in improving communication and interaction with students. Studies have found that communication and interaction increased student's motivation, engagement and understanding of course $^{29}$ and for the purpose of improving the quality of interaction, instructors shall focus more on how to utilize additional means of communication by using interactive technology programs. ${ }^{30}$

Academic staff members were also concerned about the students' achievement of the different learning outcomes in an environment where some skills remain a challenging issue to be met and evaluated. Another concern raised by students was the time management issue. The discussion also revealed that some students viewed distance education as a time-demanding process with lots of tasks to do. This was also reported as an overwhelming problem from a global perspective. ${ }^{28}$

Besides readiness and perception, barriers to the distance education process were also studied. The central areas in this domain were personal-related barriers and technical barriers. Personal related factors, for example, technology experience and motivation were regarded as minor barriers from the perspective of the two study groups. This may be due to the adequate guidance and training that were provided to academic staff and students thought out the term. Communication problems, technical issues during the teaching and assessment process, and health concerns due to the use of computers for long period were reported as barriers. These issues were emphasized on during the focus group discussion. Some ways to improve technical issues may include frequent reporting of these issues to higher administration. Additionally, ways to avoid or overcome the common issues can be distributed to academic staff and students. The participants expressed their views that they value the efforts made on different levels to improve the distance education process; however, there remain challenging issues that need to be addressed. In practice, some barriers 
are multifaceted, and addressing them needs coordination between different stakeholders, monitoring the improvement process, and having regular feedback to close the loop. Barriers to the overall teaching and assessment process during distance education are comparable on a worldwide level. ${ }^{28}$ The focus group discussions emphasized on areas to be improved which include Enhancement of distance education platforms, enhancement of the communication between academic staff and students, Enhancement of the lively interaction, more training coaches on time management during distance education, more training courses for all beneficiaries to better utilize the available resources, and more technology integration into the distance education process. Addressing these areas for improvement, in the short and long run, will profoundly reshape the picture of distance education.

Distance education is also expected to come with some perceived learning acquisitions. The flexibility of teaching from anywhere, improvement of time organization and utilization, enhancement of teaching and technology skills were viewed as accomplishments in this study from the perspective of teaching staff. Students shared comparable views with stressing on the increased value of enhancement of independent learning skills was considered. These findings are comparable to Rajab $\mathrm{MH}$ et al, 2020 who found that increasing the self-responsibilities among students is one of the advantages of distance learning. ${ }^{28}$ On the other hand, students were generally "neutral" about the "time management" and "enhancement of the acquisition of scientific knowledge" as accomplishments in their experience which is correlated with their perspective about distance education.

\section{Limitations}

The results of this study should be interpreted in light of the type of bias inherited to survey design. The findings were based on participants' self-reports, which might introduce social desirability bias. However, attempts were made to reduce the bias through the qualitative exploration of the participants' experience using focus group discussions. It is also important to consider that the experience presented here is from a female-only college. Males might have different perspectives.

\section{Conclusion}

This study reflects that shifting to distance education during the COVID-19 pandemic was positively received by academic staff and students at the College of Pharmacy -
PNU. The main outcomes indicate that both academics and students reflected positively to the readiness of shifting to distance education. For the barriers and challenges, both students and staff raise the active communication and health issues due to long time screen as the main barriers. In addition, academic staff showed concerns toward the impact of the technical issues on the teaching and assessment. For the main acquisitions, academic staff found that distance learning is an opportunity to develop their teaching skills whereas students found it as a chance to explore their independent learning skills. Lessons should be learned from this experience, and strategic plans need to be established to overcome the concerns highlighted.

\section{Disclaimer}

The work presented is solely the authors' analysis, and may not be understood or quoted as being made on behalf of or reflecting the position of the College of Pharmacy Princess Nourah bint Abdulrahman University.

\section{Acknowledgment}

This research was funded by the Deanship of Scientific Research at Princess Nourah bint Abdulrahman University through the Fast-track Research Funding Program.

\section{Disclosure}

The authors declare no potential conflict of interest relevant to this work.

\section{References}

1. Seel N. Encyclopedia of the Sciences of Learning. Springer US; 2012. doi:10.1007/978-1-4419-1428-6

2. Kentnor HE. Distance education and the evolution of online learning in the United States. Curric Teach Dialogue. 2015;17(2):21-30.

3. Suda KJ, Sterling JM, Guirguis AB, Mathur SK. Student perception and academic performance after implementation of a blended learning approach to a drug information and literature evaluation course. Curr Pharm Teach Learn. 2014;6(3):367-372. doi:10.1016/j. cpt1.2014.02.017

4. Graham CR, Allen S. Blended learning environments. In: Encyclopedia of Distance Learning. 2011. doi:10.4018/9781-59140-555-9.ch024

5. World Health Ordanization. Coronavirus disease (COVID-19). Coronavirus disease (COVID-19); 2020. Accessed November 11, 2020. https://www.who.int/emergencies/diseases/novel-coronavirus -2019 .

6. Alqurshi A. Investigating the impact of COVID-19 lockdown on pharmaceutical education in Saudi Arabia - a call for a remote teaching contingency strategy. Saudi Pharm J. 2020;28 (9):1075-1083. doi:10.1016/j.jsps.2020.07.008

7. Kawaguchi-Suzuki M, Nagai N, Akonoghrere RO, Desborough JA. COVID-19 pandemic challenges and lessons learned by pharmacy educators around the globe. Am J Pharm Educ. 2020;84 (8):1045-1048. doi:10.5688/ajpe8197 
8. Shawaqfeh MS, Al Bekairy AM, Al-Azayzih A, et al. Pharmacy students perceptions of their distance online learning experience during the COVID-19 pandemic: a Cross-Sectional Survey Study. J Med Educ Curric Dev. 2020;7:1-9. doi:10.1177/2382120520963039

9. Aristovnik A, Keržič D, Ravšelj D, Tomaževič N, Umek L. Impacts of the COVID-19 pandemic on life of higher education students: a global perspective. Sustain. 2020;12(20):1-34. doi:10.3390/su12208438

10. Coman C, Țîru LG, Meseșan-Schmitz L, Stanciu C, Bularca MC. Online teaching and learning in higher education during the coronavirus pandemic: students' perspective. Sustain. 2020;12(24):10367. doi:10.3390/su122410367

11. Hasan N, Bao Y. Impact of e-Learning crack-up perception on psychological distress among college students during COVID-19 pandemic: a mediating role of fear of academic year loss. Child Youth Serv Rev. 2020;118:105355. doi:10.1016/j.childyouth.2020.10535512

12. Bennardo F, Buffone C, Fortunato L, Giudice A. COVID-19 is a challenge for dental education - a commentary. Eur J Dent Educ. 2020;24(4):822-824. doi:10.1111/eje.12555

13. Elzainy A, El Sadik A, Al Abdulmonem W. Experience of e-learning and online assessment during the COVID-19 pandemic at the College of Medicine, Qassim University. J Taibah Univ Med Sci. 2020;15 (6):456-462. doi:10.1016/j.jtumed.2020.09.005

14. Ramos-Morcillo AJ, Leal-Costa C, Moral-García JE, RuzafaMartínez M. Experiences of nursing students during the abrupt change from face-to-face to e-Learning education during the first month of confinement due to COVID-19 in Spain. Int $J$ Environ Res Public Health. 2020;17(15):5519. doi:10.3390/ijerph17155519

15. Ward CT, Rey JA, Mobley WC, Evans CDW. Establishing a distance learning site for a traditional doctor of pharmacy program. Am J Pharm Educ. 2003. doi:10.5688/aj670120

16. Grillo JA, Stolte SK, Lewis J, Robinson ET. Integration of web-based computer-aided instruction into a nontraditional doctor of pharmacy program. J Pharm Pract. 2000;3(5):382-391. doi:10.1106/F7EHD14F-CRLR-LWGB

17. Kennedy DH, Ward CT, Metzner MC. Distance education: using compressed interactive video technology for an entry-level doctor of pharmacy program. Am J Pharm Educ. 2003;67(4):118. doi:10.5688/aj6704118

18. Khalil R, Mansour AE, Fadda WA, et al. The sudden transition to synchronized online learning during the COVID-19 pandemic in Saudi Arabia: a qualitative study exploring medical students' perspectives. BMC Med Educ. 2020;20(1). doi:10.1186/s12909-02002208-Z
19. Faulkner TP, Christoff JJ, Sweeney MA, Oliver N. Pilot study of a distance-learning methodology used on campus for first professional degree pharmacy students in an integrated therapeutics module. $\mathrm{Am}$ J Pharm Educ. 2005;69(1):55-61. doi:10.5688/aj690107

20. Lean QY, Ming LC, Wong YY, Neoh CF, Farooqui M, Muhsain SNF. Online versus classroom learning in pharmacy education: students' preference and readiness. Pharm Educ. 2020;20:19-27.

21. Adnan M. Online learning amid the COVID-19 pandemic: students perspectives. J Pedagog Soc Psychol. 2020;1(2):45-51. doi:10.33902/jpsp.2020261309

22. Bisht RK, Jasola S, Bisht IP. Acceptability and challenges of online higher education in the era of COVID-19: a study of students' perspective. Asian Educ Dev Stud. 2020. doi:10.1108/AEDS-052020-0119

23. Lyons KM, Christopoulos A, Brock TP. Sustainable pharmacy education in the time of COVID-19. Am J Pharm Educ. 2020;84 (6):667-672. doi:10.5688/ajpe 8088

24. Almaghaslah D, Alsayari A. The effects of the 2019 novel coronavirus disease (COVID-19) outbreak on academic staff members: a case study of a pharmacy school in Saudi Arabia. Risk Manag Healthc Policy. 2020;13:795-802. doi:10.2147/RMHP.S260918

25. Williamson K, Given LM, Scifleet P. Qualitative Data Analysis. 2nd ed. Elsevier Inc; 2018. doi:10.1016/B978-0-08-102220-7.00019-4

26. Bensaid B, Brahimi T. Coping with COVID-19: higher education in the GCC countries. RII Forum Athens. 2020;72:1-19.

27. Okereke M, Williams AE, Emmanuella NC, Ashinedu NU, Mairaj MW. Covid-19: challenges affecting the uptake of e-learning in pharmacy education in Africa. Pan Afr Med J. 2020;35(Supp 2):1-3. doi:10.11604/pamj.supp.2020.35.2.23910

28. Rajab MH, Gazal AM, Alkattan K. Challenges to Online Medical Education During the COVID-19 Pandemic. Cureus. 2020;12 (7):8966. doi:10.7759/cureus.8966

29. HRC THRC. Best practices in online teaching strategies. Hanaover Res Counc. 2009;35.

30. Mash B, Marais D, Van Der Walt S, Van Deventer I, Steyn M, Labadarios D. Assessment of the quality of interaction in distance learning programmes utilizing the internet or interactive television: perceptions of students and lecturers. Med Teach. 2006;28(1):e1-e9. doi:10.1080/01421590600568439
Risk Management and Healthcare Policy

\section{Publish your work in this journal}

Risk Management and Healthcare Policy is an international, peerreviewed, open access journal focusing on all aspects of public health, policy, and preventative measures to promote good health and improve morbidity and mortality in the population. The journal welcomes submitted papers covering original research, basic science, clinical \& epidemiological studies, reviews and evaluations, guidelines, expert opinion and commentary, case reports and extended reports. The manuscript management system is completely online and includes a very quick and fair peer-review system, which is all easy to use. Visit http://www.dovepress.com/testimonials.php to read real quotes from published authors. 